\title{
PARCERIA UNIVERSIDADE-EMPRESA E MUDANÇAS NA CULTURA ACADÊMICA: ANÁLISE COMPARATIVA DOS CASOS DA ARGENTINA E DO CANADÁ
}

\author{
DANIEL SCHUGURENSKY ${ }^{*}$ \\ JUDITH NAIDORF*
}

\begin{abstract}
RESUMO: Este artigo estuda as mudanças na cultura acadêmica que ocorreram nas universidades públicas nestas últimas décadas. A partir de uma perspectiva histórica e comparada (que descreve os casos da Argentina e do Canadá), analisam-se as características das universidades e da cultura acadêmica no período do pós-guerra (19501970) e do final do século (1980-2000). No contexto das políticas neoliberais de mercadorização do conhecimento, de diminuição do financiamento público e do redirecionamento dos fundos vinculados por agentes externos à universidade, um modelo de capitalismo acadêmico instaurou-se gradualmente durante esse segundo período e a universidade autônoma transformou-se paulatinamente numa universidade heterônoma.
\end{abstract}

Palavras-chave: Cultura acadêmica. Relação universidade-empresa. Autonomia. Heteronomia.

\section{UNIVERSITY-INDUSTRY PARTNERSHIPS AND CHANGES IN ACADEMIC CULTURE: A COMPaRATIVE aNALYSIS OF ARgentina AND CANADA}

ABSTRACT: This paper studies the changes in academic culture public universities have suffered these last decades. From a historical and comparative (with cases from Argentina and Canada) standpoint, it analyses the features of university and academic culture during the post-war (1950-1970) and end of century (1980-2000). In a context of neo-liberal policies that commercialize knowledge, reduce pub-

* Universidade de Toronto. E-mail: dschugurensky@oise.utoronto.ca

** Universidade de Buenos Aires. E-mail: naidorfjudith@hotmail.com

Educ. Soc., Campinas, vol. 25, n. 88, p. 997-1022, Especial - Out. 2004

Disponível em <http://www.cedes.unicamp.br> 
Parceria universidade-empresa e mudanças na cultura acadêmica...

lic funding and redirect funding according to external actors, a model of academic capitalism has gradually taken over during this last period and university has undergone a gradual shift from autonomy to heteronomy.

Key words: Academic culture. Industry-university relationship. Autonomy. heteronomy.

\section{Introdução}

$\mathcal{E}$

ste capítulo estuda as mudanças na cultura acadêmica ocorridas nas duas últimas décadas em dois países, num contexto internacional marcado pela globalização econômica, as políticas neoliberais e a falência do Estado-Providência. Em muitas universidades, essas tendências foram acompanhadas por uma crescente mercadorização do conhecimento, o declínio dos financiamentos federais e o concomitante aumento de financiamentos e contratos vinculados, uma intensificação do capitalismo acadêmico, e uma mudança gradual da autonomia para a heteronomia ${ }^{1}$ (Schugurensky, 1994; Slaughter \& Leslie, 1997; Newson \& Buchbinder, 1988, 1990); Fisher \& Rubenson, 1998; Altbach, 2002). Afirmamos que não se podem explicar as mudanças em dadas culturas acadêmicas sem levar em conta essas tendências e seus desdobramentos, como as crescentes pressōes para tornar os orçamentos "auto-sustentáveis", a multiplicação de atividades empresariais, a inclusão de ensino superior como um bem de serviço nos acordos internacionais (OMC/AGCS, por exemplo) e um clima geral favorável ao mercado.

Nesta análise, conceituamos a cultura acadêmica como os discursos, as representaçōes, as motivaçōes, as normas éticas, as concepçôes, as visōes, e as práticas institucionais dos atores universitários. Isso inclui as idéias dos acadêmicos a respeito dos objetivos de seus próprios trabalhos e das três principais funções da universidade ligadas à produção, transmissão e aplicação de conhecimentos acadêmicos (pesquisa, ensino e serviço à comunidade). As prioridades entre essas funçôes e dentro delas, numa dada instituição, são o produto de fatores internos e externos, que incluem as determinaçôes de financiamento, as políticas governamentais e as tradiçōes históricas.

Para estudar as mudanças na cultura acadêmica, oferecem-se três perspectivas principais. A primeira propõe uma explicação causal 
"determinista" que entende as mudanças na cultura acadêmica como o resultado das mudanças nas estruturas de recompensas (os contratos com a empresa para promoçōes, aumentos de salário, financiamentos para fazer pesquisa básica etc., por exemplo) e castigos (redução dos financiamentos, promoções raras, licenciamentos etc., por exemplo). Segundo essa explicação, à medida que os pesquisadores aprendem a se adaptar às novas regras, sua cultura acadêmica muda e torna-se "naturalizada".

A segunda propõe uma explicação "voluntarista", segundo a qual os acadêmicos podem muitas vezes escolher livremente o que fazer, mesmo num contexto de pressões externas. Com isso, as mudanças na cultura acadêmica são o resultado de escolhas voluntárias e conscientes feitas por vontade própria depois de uma avaliação racional dos prós e dos contras das antigas e novas regras, e da conveniência ou não de se adaptar às mudanças do mundo externo. Segundo essa tese, as universidades são instituiçôes que se autogovernam, e os acadêmicos têm o poder de definir as regras do jogo. Portanto, as recentes mudanças na cultura acadêmica podem se explicar como os esforços conscientes de acadêmicos para adaptarem instituiçôes medievais às dinâmicas do capitalismo global.

A terceira abordagem, que reconhece as contribuições parciais das duas visões acima, consiste numa perspectiva dialética fundada numa teoria de conflito que identifica uma interação constante entre estrutura e agente. Segundo essa explicação, que nos parece mais convincente, as mudanças na cultura acadêmica surgem num contexto de disputas e negociações constantes entre as pressões externas e as escolhas éticas e intelectuais dos pesquisadores acadêmicos. Como adota esta abordagem, nossa análise é circunscrita por seis hipóteses que dela decorrem:

1. Embora seja possível falar em "cultura acadêmica" em termos gerais, qualquer instituição pode abrigar várias culturas acadêmicas (no plural). Não estamos falando apenas das "duas culturas" discutidas por C.P. Snow em 1959 (ciências e humanidades), mas também das diferentes maneiras de entender e empreender o trabalho acadêmico, tal como ser desejável ou não estabelecer vínculos mais estreitos com a empresa.

2. Embora várias culturas acadêmicas possam conviver em qualquer meio institucional, em certos períodos históricos podese identificar uma cultura acadêmica particular como domi- 
Parceria universidade-empresa e mudanças na cultura acadêmica...

nante ou hegemônica, e outras que são subordinadas ou marginais.

3. Essa relação pode mudar com o tempo: uma cultura acadêmica subordinada pode se tornar dominante, e vice-versa. Essas mudanças podem ser demoradas e imperceptíveis, ou rápidas e dramáticas (em razão de mudanças bruscas no regime político ou econômico, e/ou do surgimento de um novo conjunto de alianças, práticas institucionais e estruturas de recompensas, por exemplo).

4. As novas gerações de pesquisadores que são expostas apenas ao conjunto hegemônico de práticas e valores são mais propensas a aceitá-los que as gerações mais antigas que também conheceram valores e práticas antigos. À medida que essa geração mais antiga de acadêmicos se aposenta, os novos valores e práticas passam a ser aceitos como "normais".

5. As culturas acadêmicas não são fixas nem imutáveis, e sua evolução é o produto da resistência e da acomodação a novos ambientes, regras, práticas e idéias, num processo caracterizado por mecanismos contraditórios de conflitos, negociação e consenso.

6. Embora as culturas acadêmicas sejam moldadas por fatores externos como políticas governamentais, práticas empresariais ou ideologias predominantes na sociedade, elas podem, ao mesmo tempo e numa relação dialética, influenciar políticas, práticas e ideologias externas.

Com base em dados coletados em fontes primárias e secundárias (que incluem mais de 70 entrevistas semi-estruturadas com acadêmicos argentinos e canadenses), afirmamos que uma mudança na cultura acadêmica foi acontecendo nesses dois países pelo menos desde o começo dos anos de 1980. Durante o período pós-guerra (dos anos de 1950 aos anos de 1970) a cultura acadêmica dominante desses dois países era quer indiferente quer contra o estabelecimento de vínculos mais estreitos com a empresa. Entretanto, nas duas últimas décadas do século XX, muitos acadêmicos começaram a aceitar esses vínculos como uma realidade inevitável e muitas vezes até desejável. Vale notar três características interessantes nessa mudança. Primeiro, sua natureza 
profunda com relação às tradições estabelecidas do passado. Segundo, a velocidade incrível com que ocorreu, em comparação com as mudanças de cultura acadêmica anteriores. Terceiro, a ausência de debate, quer dentro ou fora da academia, sobre estas questôes.

\section{O raciocínio por trás das relações universidade-empresa}

Nestas últimas décadas, as universidades foram pressionadas pelos governos para estabelecerem vínculos mais fortes com a empresa e buscar fontes alternativas de financiamento. A idéia de criar laços entre a universidade e a empresa remonta pelo menos a Comte que, em 1819, publicou um plano para homens de negócios, industriais e tecnólogoscientistas, que seriam representados em três câmaras. Muitas vezes (independentemente de o país ser capitalista ou socialista), esse modelo tomou a forma de programas de educação "cooperativa", na qual os alunos dividiam seu tempo entre sala de aula e fábrica, com um currículo moldado para responder às necessidades desta última.

Nos anos de 1980, esse modelo tradicional foi substituído por um novo modelo (muito mais profundo e global) caracterizado pela intensificação da transferência de tecnologia das universidades para a empresa e a comercialização do trabalho acadêmico. Desde então, mais pesquisadores começaram a transferir seus resultados para empresas industriais, e novos escritórios foram construídos nos campi universitários para fortalecer os vínculos entre empresas e universidades como transferência de tecnologia, gerenciamento de contratos, patenteamentos e licenciamentos, desenvolvimento internacional e cooperação industrial.

Em muitos casos, as empresas particulares forneciam capitais ou financiamentos operacionais às universidades em troca de uma influência na direção das pesquisas e licenças exclusivas sobre as descobertas patenteáveis feitas nos laboratórios. O raciocínio por trás dessas determinações é que o sistema de conhecimento necessário para apoiar a área de P\&D depende de interações oportunas, freqüentes e informais entre pesquisadores e quem está na prática. Parte-se do princípio de que essas interaçōes podem favorecer o surgimento de novas idéias, relações e abordagens comerciais (Lindenstein \& Walshok, 1990). A intensificação das relações universidade-empresa é particularmente evidente nos EUA, onde dezenas de universidades estão se dirigindo a empresas pri- 
Parceria universidade-empresa e mudanças na cultura acadêmica...

vadas (especialmente farmacêuticas e eletrônicas) para obter ganhos [financeiros] de suas pesquisas científicas (Tornatzky et al., 2002).

Esses contratos cada vez mais numerosos com clientes externos - e a mudança geral rumo a uma universidade mais empresarial - são inseparáveis da crença neoliberal na superioridade das dinâmicas do mercado sobre a autonomia acadêmica, a qual é percebida como fundamentalmente irrelevante e centrada em si mesma. Um pressuposto relacionado é que o setor privado é sempre mais eficaz e eficiente que o setor público, considerado inerentemente desperdiçador, ineficiente e corrompido. Essas crenças levaram a demandas por mais universidades privadas e por mais empreendedorismo nas universidades públicas. Em termos de relações universidade-empresa, um pressuposto-chave por trás dessas demandas é que, quando se estimula a concorrência entre fornecedores, o mercado encarrega-se de recompensar a eficiência e punir a ineficiência. Conseqüentemente, ainda segundo este argumento, as universidades deveriam ser pressionadas para se tornarem mais empresariais e oferecerem seus serviços e produtos (pesquisa, consultoria, formação etc.) a um imenso leque de consumidores (inclusive ao governo), numa busca por bens da maior qualidade pelo menor preço (Walford, 1991). Veremos agora como esse raciocínio foi aplicado em nossos dois estudos de casos.

\section{Argentina}

Herdeiras do modelo napoleônico e da progressista Reforma de Córdoba, de 1918, ${ }^{2}$ as universidades argentinas conheceram uma "época áurea” no período pós-guerra, com pesquisa de altíssima qualidade, comparável aos padrões internacionais, um nível acadêmico elevado e um modelo democrático sustentado de autogoverno que incluía professores, estudantes e alunos. Nos anos de 1950, isso coincidiu com o desenvolvimento modernizador que promovia um modelo de industrialização por substituição das importações. Como parte dessa estratégia, o Estado criou grandes instituições científico-tecnológicas extra-universitárias para cuidar das atividades de $P \& D$ em campos específicos como a agricultura, a indústria, a energia atômica e a pesquisa básica. Enquanto isso, as universidades públicas continuavam sendo importantes centros de pesquisa, e os números de matrículas aumentavam à medida que as novas classes médias começavam a ter acesso ao ensino superior. 
Esse processo foi dramaticamente interrompido em julho de 1966, quando os militares invadiram a Universidade de Buenos Aires, agredindo e prendendo alunos e professores, inclusive professores-visitantes internacionais. Isso marcou o início de um novo período caracterizado pela intervenção de governos militares nas universidades públicas, os quais, entre outras coisas, impuseram autoridades acadêmicas e passaram a controlar os currículos e as agendas de pesquisa. A intervenção militar também revogou a Lei sobre as Universidades (University $A(t)$, reduziu o número de matrículas e provocou o colapso virtual da comunidade científica. Durante esse período, as atividades de pesquisa foram solapadas por reduções nos financiamentos, pela repressão brutal da dissidência, pelo primeiro êxodo maciço de professores e cientistas argentinos e pela semiparalisia de várias instituições de pesquisa criadas nos anos anteriores como o INTI, a CNEA, o INTA e o CONICET (Grupo de Trabajadores de la Ciencia, 1972).

Nas duas décadas que seguiram essa intervenção militar de 1966, a vida acadêmica argentina passou por duas ditaduras militares (19661973 e 1976-1983), com um breve governo democrático entre elas. Durante o primeiro regime militar (1966-1973), apesar da intervenção na universidade e do clima repressivo, alguns círculos de acadêmicos e intelectuais prestigiosos conseguiram permanecer ativos. Alguns deles, ligados a um movimento conhecido como "Pensamiento Latinoamericano en Ciencia y Tecnología”, promoviam debates animados e análises perspicazes sobre as relações entre pesquisa universitária, políticas de desenvolvimento, empresas estatais e necessidades societais. Eles também estimularam programas de extensão inovadores que amparavam populaçóes marginalizadas.

Muito diferentemente, o regime militar de 1976 a 1983 foi particularmente nocivo para o desenvolvimento de trabalhos intelectuais. Como na ditadura anterior, a pesquisa científica e a produção cultural nas universidades públicas foram sufocadas por cortes nos orçamentos e intervenções, mas dessa vez a repressão da dissidência e a censura foram muito mais longe, transformando aquela época na mais sombria e violenta do passado recente da Argentina. Naqueles anos houve pouco espaço para debates acadêmicos, uma vez que muitos membros da comunidade universitária estavam mais preocupados com a própria sobrevivência que com pesquisa ou tentativas de encontrar visões alternativas. Essa ditadura não resultou apenas na agonia da cultura acadêmica 
Parceria universidade-empresa e mudanças na cultura acadêmica...

como também projetou e implantou um aparato sistêmico de terrorismo de Estado que torturou, assassinou e fez desaparecer 30 mil pessoas, entre as quais $21 \%$ eram estudantes. As universidades tornaram-se parte da "doutrina nacional de segurança", que impunha a repressão física dos dissidentes, a interdição e a destruição de muitos livros, a abolição da autonomia da universidade, interrogatórios de professores pelos serviços secretos, a censura de teorias como a do materialismo histórico e a da psicanálise, e um ataque conservador contra disciplinas como sociologia, psicologia e antropologia. Em 1983, a democracia eleitoral foi restabelecida, e seguiram-se duas décadas de receita neoliberal e reajustes estruturais que encolheram mais ainda os orçamentos do ensino superior, limitando as possibilidades de realizar pesquisas independentes de alta qualidade em instituições públicas e estimulando os acadêmicos a estabelecerem vínculos mais estreitos com o mercado.

\section{Relações com as empresas}

Em 1983, o governo Alfonsín criou uma Oficina de Transferência de Tecnologia, inaugurando um novo ciclo nas relaçôes universidadeempresa na Argentina. Com sede no Conselho Nacional de Pesquisa, essa Oficina era concebida como uma iniciativa crucial para atrair financiamentos privados nos orçamentos universitários, e para revitalizar a empresa nacional depois de duas décadas de constante declínio. Esse evento foi um divisor de águas simbólico nas relações universidade-empresa. Nas décadas anteriores, essas relações haviam sido mais exceção que norma, e isso por várias razóes.

Primeiro, elas eram percebidas como prejudiciais à pesquisa, a qual era essencialmente concebida como livre de pressóes externas e restrições, movida apenas pelo desejo de conhecer, e regida por regulações a respeito de como novos conhecimentos eram produzidos em cada disciplina. $\mathrm{O}$ ethos da pesquisa universitária baseava-se nos princípios da autonomia e da ciência para o bem do conhecimento.

Segundo, estabelecer parcerias com a empresa era visto como uma ação nociva, suspeita, que os pares podiam julgar como um ato de corrupção. "Naquela época", disse um entrevistado, "o utilitarismo da pesquisa universitária não era visto com bons olhos”. Nivoli (1992) con- 
firma que, antes de 1980, a transferência de tecnologia era considerada um "palavrão" nos círculos científicos.

Terceiro, muitos cientistas, pesquisadores, professores, administradores e alunos viam o setor dos negócios (e particularmente as empresas estrangeiras) com desconfiança. Naquele contexto, o único tipo aceitável de relação formal com a empresa era com empresas estatais. $\mathrm{O}$ raciocínio era que a relação entre universidades públicas e empresas públicas condizia com a missão de serviço público. Esta orientação terminou nos anos de 1990, quando a maioria das empresas estatais foi privatizada e vendida a preço vil para firmas estrangeiras.

Quarto, a relação entre universidade e empresa não era considerada uma questão importante quando se pensava em políticas científicas e tecnológicas. Além dos apelos para apoiar as empresas estatais, não havia uma teoria sistêmica, um quadro conceitual global, ou um aparato ideológico sobre esse assunto. Como resultado, essa relação não era valorizada pelos atores universitários, nem era transcendida por uma política científica e tecnológica geral.

Quinto, havia pouca pressão dos atores externos, uma vez que a empresa (e o setor comercial em geral) não fazia lobby contra as universidades para exigir uma abordagem institucional e promover vínculos sistêmicos. Essa indiferença pode ser parcialmente explicada pelo tradicional desinteresse da empresa em investir em P\&D, e parcialmente pela percepção de que estabelecer parcerias com a universidade pública iria contra seus interesses. Como disse um industrial: "Que garantia tínhamos, nós industriais, de que os resultados de pesquisa seriam mantidos em segredo até obtermos um retorno do investimento? Se as descobertas são publicadas, a concorrência tem livre acesso a elas".

Sexto, como resultado da ausência de um quadro conceitual para nortear essa relação, e da pressão fraca da empresa, as poucas relações existentes não tinham um quadro institucional que as fomentasse e apoiasse. Os raros contratos que unidades acadêmicas assinavam com o setor produtivo costumavam passar por canais informais. Como um pesquisador mais antigo observou: "Antes de começarem a desenvolver uma política explícita para as relações universidade-empresa, poderíamos provavelmente achar alguns 'lindos' exemplos de relaçôes bem-sucedidas, nesta universidade. Contudo, na maioria dos casos, resultavam de iniciativas ad hoc de pesquisadores, ou do acaso, mas não de uma política explícita”. 
Parceria universidade-empresa e mudanças na cultura acadêmica...

Finalmente, os pesquisadores que já tinham vínculos com a empresa relutaram em institucionalizar essas relações. Esses grupos de pesquisa conseguiam gerenciar projetos de pesquisa com financiamento externo, mas muitas vezes fora de qualquer orçamento oficial. Preferiam mantê-los longe dos olhos da comunidade universitária. Do ponto de vista dos pesquisadores, ajudavam a universidade, pois contratavam alunos de pós-graduação como assistentes de pesquisa, compravam equipamentos para os laboratórios, drogas para os experimentos e até pagavam manutençóes básicas como o conserto de janelas. Do ponto de vista das autoridades universitárias, contudo, esses projetos eram operações particulares semiclandestinas cujos orçamentos constituíam uma "caixa-preta" desconhecida de todos, menos dos pesquisadores. Os administradores universitários também percebiam que esses grupos de pesquisa estavam fazendo algo de profundamente antiético, pois usavam a infra-estrutura e as instalaçôes públicas para obterem lucro privado. Como uma alta burocrata da maior universidade argentina nos disse: "Esses pesquisadores não queriam que os recursos obtidos graças a esse tipo de acordos fossem visíveis, porque naqueles tempos de penúria ninguém revelava suas fontes ou financiamentos". Outro administrador acrescentou:

O fato de que não havia canais institucionais não significa que a transferência não existia. Existia, mas por meio de acordos privados. Aliás, quantas vezes não pensamos que os pesquisadores vendiam seu trabalho a preço vil, para conseguir alguns tostōes. Eles faziam tudo errado. A idéia para além de sua institucionalização e da instauração de um certo controle sobre o fluxo de recursos da universidade também era dar-lhes mais valor e reconhecimento.

Durante o primeiro governo democrático (1983-1988), o Conselho Argentino para Pesquisa Científica e Tecnológica começou a organizar um quadro coerente da experiência das transferências de tecnologia que tinha sido acumulada durante o período militar. Em 1987, a Universidade de Buenos Aires criou a Dirección de Convenios y Transferencias, institucionalizando mais ainda a relação com a empresa.

Em 1990, com a posse de um novo governo, esse processo de institucionalização recebeu um novo impulso. Primeiro, a Resolução n. $787 / 90$ provia o primeiro quadro regulatório para melhorar os vínculos entre a Universidade de Buenos Aires e a empresa. ${ }^{3}$ Estabelecia que 
os lucros oriundos da comercialização de resultados de pesquisa deveriam ser distribuídos de modo específico. Quarenta por cento seriam destinados ao departamento do grupo de pesquisa, 20\%, a um fundo especial para P\&D e $40 \%$ seriam divididos entre professores titulares (aproximadamente $10 \%$ de todos os professores) como abono salarial (Naidorf, 2002).

Segundo, a Lei n. 23.877, de 1990, estabelecia a possibilidade de criar Unidades de Vinculación Tecnológica. Pela primeira vez, essa legislação previa a possibilidade de conceder compensações monetárias adicionais a um cientista envolvido em um projeto de pesquisa financiado pela empresa. Isso estava relacionado a um modelo de isenção fiscal para as empresas que trabalhavam com essas Unidades.

Terceiro, em 1990, a primeira Unidad de Vinculación Tecnológica da maior universidade (Universidad de Buenos Aires, ou UBA) foi criada com o nome de UBATEC S.A. Era concebida como uma empresa formada pela Universidade de Buenos Aires, a Associação Argentina da empresa e a Municipalidade de Buenos Aires para comercializar a produção de pesquisa universitária. Em 2003, havia quase 100 empresas como a UBATEC no país. ${ }^{4}$

Quarto, uma das mais importantes políticas científicas do começo dos anos de 1990 foi a criação do FONTAR ${ }^{5}$ e do FONCYT. ${ }^{6}$ Essas duas instituiçōes se tornaram os novos gerentes (substituindo o CONICET) de muitos financiamentos públicos destinados especificamente aos vínculos tecnológicos com a empresa. O FONTAR buscava financiar projetos cujas metas eram a inovação e a modernização tecnológica de empresas do setor privado. As empresas argentinas podiam se candidatar a certificados de crédito fiscal para pesquisa básica e aplicada, pesquisa précompetitiva, adaptação tecnológica e melhorias. O FONCYT objetivava patrocinar grupos de pesquisa em C\&T que trabalhavam com organizaçóes sem fins lucrativos, privadas ou públicas, cuja proposta era gerar novos conhecimentos. Os financiamentos eram destinados a projetos de pesquisa básica ou aplicada passíveis de serem publicadas em revistas especializadas, ou para que empresas e instituições desenvolvessem tecnologias potencialmente aplicáveis em conjunto.

Durante os dois mandados presidenciais de Menem, nos anos de 1990, esse quadro legal foi associado a cortes regulares dos orçamentos destinados às universidades e aos serviços sociais e à privatização de 
Parceria universidade-empresa e mudanças na cultura acadêmica...

muitas estatais e órgãos públicos. O governo até chegou a propor um projeto de lei para privatizar o sistema argentino de pesquisa. O raciocínio subjacente a essa iniciativa fracassada era que, se o sistema de pesquisa passasse para o setor privado, a pesquisa universitária poderia se tornar mais relevante para a empresa local, o que partia do pressuposto de que a empresa local tinha interesse em financiar os esforços de pesquisa. ${ }^{7}$

Juntos, a ideologia neoliberal do governo, a crise orçamentária da universidade e o quadro regulatório instaurado pressionaram os acadêmicos para que reorientassem seus objetivos de pesquisa para o mercado ou, pelo menos, para que pensassem em estratégias para tornar suas pesquisas mais vendáveis. Está certo que em algumas unidades universitárias a resistência contra o financiamento privado era (e ainda é) viva e forte (para preservar a universidade gratuita, por exemplo), e algumas reservas contra a pesquisa patrocinada surgiram a respeito de questóes como conflitos de interesses ou o sigilo dos resultados de pesquisa. Entretanto, em termos gerais, está claro que a cultura acadêmica argentina passou por mudanças importantes. A nova orientação para o mercado afetou-a em quase todas as disciplinas, mesmo se isso é particularmente evidente em áreas como as de engenharia, farmacologia e ciências naturais (física, química, biologia, por exemplo).

Nos departamentos de pesquisa intensiva, as demandas por transformações sociais e pesquisa independente, típicas dos anos de 1960 e 1970 , foram substituídas por uma abordagem mais pragmática que focalizava sobretudo a pesquisa patrocinada com aplicaçóes comerciais. Além do mais, em contraste com os sentimentos antiimperialistas dos anos de 1960 e 1970, muitos acadêmicos, hoje em dia, buscam assinar contratos com multinacionais, por causa de sua maior capacidade para financiar atividades de pesquisa relativas à empresa nacional. Vale notar que os debates sobre os perigos potenciais de uma universidade heterônoma têm se focado mais, até agora, no intervencionismo do Estado que na comercialização de atividades acadêmicas. Na Argentina, por causa da relação longa e tensa entre as universidades e o Estado e da curta história das relações universidade-negócios, isso não é muito surpreendente. Contudo, uma preocupação crescente já pode ser observada entre os dirigentes universitários. $\mathrm{O}$ reitor da maior e mais influente instituição de ensino superior, a Universidade de Buenos Aires, por exemplo, alertou que, em sua busca frenética por recursos privados, as universidades podem acabar se transformando em criados da 
empresa, que vendem suas almas ao mercado e perdem sua raison d'être [razão de ser]:

As enormes restrições orçamentárias forçam as universidades a buscarem recursos desesperadamente. Nessa busca, estão perdendo muito de sua essência. As universidades não devem ser vistas como empresas, mas como âmbitos culturais. Essa cidade intelectual livre, como sempre se concebeu a universidade, está sendo brutalmente desmembrada pelas forças de mercado. Com isso, ela está se transformando num mero prestador de serviços educativos. Acredito que a universidade é outra coisa. (Etcheverry, 2003) ${ }^{8}$

Ora, muitos dos acadêmicos ativamente engajados em pesquisas que envolvem universidades e empresas não estão muito preocupados com essa perspectiva. Em público, tendem a argumentar que conseguem assumir contratos comerciais e conservar sua liberdade acadêmica, e conseguem manter um equilíbrio entre pesquisas comerciais e pesquisas de seu interesse. Já em particular, muitos reconhecem que, no contexto atual, tendem a dedicar mais tempo e energia às pesquisas patrocinadas ou com potencial comercial.

\section{Canadá}

Durante os anos de 1960 e 1970, norteados pelas doutrinas predominantes da teoria do capital humano e da meritocracia, as universidades canadenses integravam em sua missão o duplo objetivo de servir às necessidades da economia e de democratizar a sociedade. Nesse contexto, o aumento de matrículas dos anos de 1960 justificava-se em termos de desenvolvimento econômico e democratização societal (Newson $\&$ Buchbinder, 1988). Por um lado, investimentos maciços de fundos públicos justificavam-se pela necessidade de dispor de uma mão-deobra altamente qualificada e instruída para contribuir com a saúde econômica do país. Por outro, enfatizava-se que as universidades deveriam desempenhar um papel democratizante e oferecer oportunidades para uma mobilidade social, política e econômica, promover rigorosos debates públicos e constituir um exemplo de autogovernança democrática (alguns comentaristas desse período se referiam à universidade como a um movimento social democrático ${ }^{9}$ ).

Naqueles anos, os princípios de autonomia institucional e de liberdade acadêmica estavam claramente embutidos nos valores e nas 
Parceria universidade-empresa e mudanças na cultura acadêmica...

práticas dos atores universitários, entre os quais muitos insistiam que a universidade deveria manter-se à distância do complexo militar/industrial, e que deveria evitar vincular-se ao mercado. No início dos anos de 1980, entretanto, posta em xeque por um novo ambiente político, econômico e cultural, a dupla hegemonia do projeto de desenvolvimento econômico e do projeto democratizante começou a desmoronar. Um novo modelo de universidade baseado em controles do governo e na comercialização emergiu, freqüentemente justificado por um discurso que apelava para os princípios amplamente aceitos de "responsabilidade" e "relevância".

Desde então, as universidades canadenses foram estimuladas a estabelecer relações mais intensas com o mercado. Para evitar que os acadêmicos relutem em tomar esse caminho por conta própria, os governos já os pressionaram ao imporem cortes orçamentários significativos, que colocaram várias universidades numa situação financeira preocupante. Em 1991, o governo federal decidiu congelar os repasses de Established Programs Financing (EPF - Financiamento de Programas Estabelecidos) per capita para instituições de ensino superior por cinco anos, o que levou a uma queda de $7,7 \%$ nos financiamentos naquele mesmo ano (Canadian Association of University Teachers - CAUT [Associação Canadense dos Professores Universitários], 1992). Em algumas províncias, como na de Ontário, nenhum outro setor que recebia repasses sofreu tanto, nos anos de 1990, como o financiamento das universidades. À medida que os orçamentos operacionais estavam diminuindo, as mensalidades e as matrículas aumentavam, e em apenas uma década os números médios de alunos por sala de aula e a proporção alunos/faculdade praticamente duplicaram, forçando as universidades a compensarem os cortes com rendas próprias, que exigiam certas recompensas em retorno (Jacek, 2003; Wiseman, 2003).

\section{Relações com as empresas}

No Canadá, um momento simbólico na instauração de uma nova relação universidade-empresa foi o Corporate-Higher Education Forum (Fórum Empresas-Ensino Superior), em 1983. Seguindo o modelo de um fórum semelhante ao que ocorrera nos EUA em 1978, ele contribuiu para criar um ambiente favorável a reforçar os vínculos entre pesquisadores universitários e empresas, e harmonizar as atividades uni- 
versitárias com o mercado. A aliança que se estabeleceu entre determinados setores de negócios e dirigentes universitários foi tão forte que o presidente do fórum observou que, durante as discussōes, era quase impossível distinguir quem era reitor de uma universidade de quem era presidente de uma empresa (Newson \& Buchbinder, 1988). Entre as recomendações estipuladas pelo fórum estavam políticas que promoviam cortes de financiamento, a competição institucional, indicadores de desempenho e uma cooperação mais estreita com os negócios.

$\mathrm{Na}$ esteira dessas recomendações veio a promoção explícita de um modelo de "universidade de serviços", experimentado na Universidade de Waterloo. Nesse modelo, analisado por Newson \& Buchbinder (1988), as empresas privadas fornecem capitais ou financiamentos operacionais às universidades em troca de influência sobre a direção de pesquisa e licenças exclusivas sobre as descobertas patenteáveis realizadas nos laboratórios. Como parte desse mesmo processo, não apenas os financiamentos alocados aos vários centros de excelência em pesquisa foram drasticamente reduzidos, mas esses centros foram pressionados para mudar da pesquisa básica para pesquisas aplicadas. Assim, os novos programas deviam não somente responder a "necessidades societais" específicas, mas ainda oferecer pelo menos promessas de oportunidades empresariais antes de poderem receber o suporte financeiro do governo (Calvert \& Kuehn, 1993; Turk, 2000). ${ }^{10}$

As universidades nem sempre foram passivas com relação às pressões externas. Às vezes, foram agentes ativos num processo de autotransformação em que a racionalização imposta por meio do orçamento e a vinculação com empresas se tornaram meios de sobrevivência institucional. Em conseqüência, as universidades estão hoje em dia começando a funcionar menos como instituiçôes cuja essência deriva de seus compromissos educativos e científicos e mais como negócios que prestam serviços educativos e geram produtos baseados no conhecimento (Newson, 1998; Polster, 1994; Fisher \& Rubenson, 1998). Janice Newson (1998) descreve assim alguns elementos da nova cultura acadêmica:

Hoje, junto com muitos desses mesmos colegas, encontro-me em reuniões de departamento ou da faculdade engajada em debates para saber como poderíamos remodelar nossos currículos acadêmicos para melhor adaptálos às exigências do "mercado externo". Tentamos justificar nossas estraté- 
Parceria universidade-empresa e mudanças na cultura acadêmica...

gias pedagógicas em termos de medidas de eficácia e de rentabilidade. Reformulamos nossos interesses de pesquisa para que se encaixem nos objetivos políticos mais recentemente anunciados por vários ministérios que estão profundamente envolvidos (quando não partem deles) com as Diretrizes dos Programas de Financiamento do SSHRC (Social Sciences and Humanities Research Council of Canada [Conselho Canadense de Pesquisa em Ciências Sociais e Humanas]), NSERC (Natural Sciences and Engineering Research Council [Conselho de Pesquisa em Ciências Naturais e Engenharia]) ou MRC (Medical Research Council of Canada [Conselho de Pesquisa Médica do Canadá]). Tentamos definir os "produtos" de nossas atividades intelectuais, quer de ensino ou pesquisa, para que possam atrair e servir às necessidades de clientes empresariais potenciais ou encaixar-se em "nichos" de mercado prescritos.

Segundo ela, esse contexto produziu um ambiente em que as tomadas de decisão colegiadas estão postas em xeque por uma agenda de cima para baixo controlada pela administração central, e em que os alunos são tratados mais como consumidores de produtos - ou até mesmo como produtos - que como participantes ativos da academia. Essas mudanças não se limitam a determinações institucionais internas; também afetam as relações entre acadêmicos e órgãos externos como as agências de financiamento, as empresas privadas e os consórcios de pesquisa nacionais e internacionais. Essas relações estão sendo reconstruídas por meio de várias políticas, determinações de financiamento, práticas e discursos que têm implicações diretas na agenda universitária e em seu papel na sociedade (Polster, 1994; Newson, 1998). Um exemplo da natureza das mudanças que ocorreram nas instituiçóes de pesquisa durante as últimas décadas pode ser encontrado no National Research Council of Canada (NRC - Conselho Nacional de Pesquisa do Canadá). Durante um grupo-teste que organizamos com administradores seniores, um deles lembrou que, nos anos de 1970, o NRC era dirigido de maneira muito semelhante a uma universidade:

Todo mundo estava fazendo pesquisa de longo prazo, ninguém estava interagindo com a empresa e isso criava um ambiente universitário ótimo, muito agradável. Aí disseram: "Isso não vai funcionar porque eles têm de enfrentar o mundo real, entender os verdadeiros desafios, interagir com a empresa e escutar a empresa".

Então, as regras do jogo mudaram, e junto com elas a estrutura de recompensas e castigos. $\mathrm{O}$ modelo tradicional de promoções (basea- 
do apenas nas publicações) foi substituído por um pacote misto de publicações, transferência de tecnologia e interações com empresas. Os pesquisadores mais antigos, em particular, tiveram muita dificuldade para se adaptarem às novas determinações institucionais, e muitos deles (em torno de $80 \%$ ) preferiram se afastar. Um participante descreveu assim aquele momento:

Então, o que tínhamos eram esses cientistas mais antigos que só sabiam escrever artigos. Muitos deles foram embora. Eles diziam: "Não vou fazer isso, vai arruinar minha carreira, quero fazer minhas próprias pesquisas, me deixem em paz no meu laboratório. Não quero interagir com a empresa. Só quero mesmo é continuar fazendo o que estou fazendo”.

O restante dos pesquisadores mais antigos teve de aprender novas regras e papéis para se adaptar ao sistema emergente:

Em torno de $20 \%$ deles ficaram, e conseguiram mudar, de modo que todo ano se exigia mais e mais deles. Ainda tinham de produzir artigos, mas também haviam de interagir com as empresas. Assim, tiveram de participar de reunióes de diretoria, sentar-se e falar com eles, tiveram de sair e fazer apresentações. Não era uma obrigação, mas, se quisessem promoções, ajudava. Pois, "se vocês tomam a tecnologia que produziram e a transferem para a empresa, têm de aprender muitas novas competências, para que nós [o NRC] tenhamos cursos. Aí, quando vocês a transferem para a empresa, vocês ganham royalties, e os royalties são um retorno: $50 \%$ vão para o NRC, $35 \%$ para o cientista e $15 \%$ para o programa”.

O processo de mudanças culturais levou aproximadamente 10 a 15 anos para se completar, pois a velha geração acabava se aposentando e a nova geração aceitava como naturais as únicas regras do jogo que conhecera. Isso criou um cenário de pesquisa dominado por uma cultura acadêmica empresarial, caracterizada por um trânsito mais fluído entre universidades e negócios:

Hoje em dia, os cientistas que vão atrás do NRC sabem que esta é a situação e que são jovens empresários. Agora, eles têm uma outra situação diante deles: agora, há umas pessoas que estão fazendo isso e estão pensando: "Espere aí, estou tirando apenas 35\% disso... Poderia ter 100\%... Então, o que quero poder fazer é pegar minha tecnologia, ir embora com ela e montar minha própria empresa”. Aí o NRC diz: "Tudo bem, sem problema”. Então, as opções são que os cientistas podem ficar e fazer seu trabalho por 
Parceria universidade-empresa e mudanças na cultura acadêmica...

$35 \%$, ou pegar sua tecnologia, ir embora e montar suas próprias firmas e fazer muito mais. Mas aí também têm de assumir todos os riscos.

Os governos das províncias desempenharam um papel importante para estreitar os vínculos universidade-empresa. Em Ontário, por exemplo, um impulso maior para estreitar essas relações veio em 1990 (curiosamente, no mesmo ano em que uma série de leis e políticas semelhantes foi proposta na Argentina), quando o vice-ministro (deputy minister) da Educação percebeu que a demanda de ensino superior estava crescendo de modo exponencial. ${ }^{11}$ Diante desse aumento da participação no ensino superior, os "fazedores" de política (policy-makers) canadenses consideraram que a participação do governo nesses custos não poderia acompanhar esse aumento por razões práticas e éticas. Praticamente, não seria uma decisão viável, pois os contribuintes se sentiriam onerados demais, e aumentar os impostos seria um suicídio político. Eticamente, argumentava-se que pedir que os contribuintes financiassem a expansão das universidades significava pedir que os pobres subsidiassem a elite. As mensalidades e matrículas apenas poderiam aumentar até certo limite e, portanto, sua participação no orçamento geral seria irrelevante. Conseqüentemente, tornava-se inevitável que as universidades e faculdades fossem buscar financiamentos complementares no setor privado.

Então, o Estado de Ontário criou o Partnership Development Branch (Departamento de Desenvolvimento de Parcerias), uma unidade do Ministério da Formação, das Faculdades e Universidades que durou dois anos e meio antes de ser extinto e absorvido por outro departamento. Essas parcerias incluíam tanto a pesquisa como o ensino. Quando, por exemplo, uma empresa doava novas tecnologias a uma instituição de ensino superior, estas seriam utilizadas para a formação dos funcionários da empresa e pelos alunos da universidade. Em razão do ritmo muito rápido das mudanças tecnológicas, esse modelo era percebido como uma situação em que todos tinham a ganhar. As empresas privadas teriam um lugar onde professores universitários com acesso a tecnologias de última geração poderiam ensinar seus funcionários, e quando estes não as usassem, elas poderiam ser aproveitadas pelos alunos da universidade. Assim, os melhores alunos de pós-graduação poderiam achar uma vaga na empresa. Isso era diferente do modelo tradicional de empresas que doavam equipamen- 
tos para instituições de educação. Como observou um dos nossos entrevistados: "Não é que a universidade ou faculdade está recebendo um presente da empresa; estão trabalhando juntas para garantir uma mão-de-obra melhor formada tanto para a firma como para os alunos em formação".

Uma outra maneira em que esta difere do modelo anterior é que os professores universitários e os formadores das empresas acabaram se misturando: "No Canadá, podíamos ver professores universitários trabalhando lado a lado com as empresas e a indústria. Às vezes ficava difícil saber quem era universitário e quem era de uma empresa”.

Estas e outras parcerias foram mais tarde estimuladas não apenas pelo Ministério da Educação, como também por outros órgãos como o Ministério da Energia, Ciência e Tecnologia, os Centros de Excelência, ou o Ministério dos Empreendimentos, Oportunidades e Inovações (exMinistério do Desenvolvimento Econômico e do Comércio). Essas relações estão evoluindo incessantemente e têm impactos diferentes em distintas áreas da universidade. Os acadêmicos em ciências sociais e humanas têm pouca experiência desses desenvolvimentos, mas em campos como a engenharia, a biologia e a medicina o impacto é mais evidente. Como disse um dos nossos entrevistados: "(...) isso causou algumas tensões dentro da instituição porque alguns professores viram isso como uma intrusão, enquanto outros pensavam 'é assim que se faz negócios”".

À luz dessa observação, seria interessante revitalizar o debate sobre as duas culturas - inaugurado por C.P. Snow em 1959 - para entender melhor essas diferenças no presente contexto, tanto em termos de ensino como de pesquisa.

Em suma, o modus operandi das universidades canadenses está mudando, assim como a cultura de suas comunidades. Como Fisher $\&$ Rubenson (1998) observaram, as universidades canadenses estão ficando mais comerciais e empresariais, e estão se afastando de sua tradicional "missão civilizatória". Eles alegam que à medida que as universidades estabelecem relaçôes mais estreitas e responsáveis com a empresa, e tentam se adaptar de modo mais deliberado às necessidades comerciais, elas estão perdendo sua autonomia. Isso confirma nossa hipótese de que esses desenvolvimentos estão acelerando a transição rumo a um modelo institucional heterônomo. 
Parceria universidade-empresa e mudanças na cultura acadêmica...

\section{Resumo e conclusões}

Dos anos de 1950 aos de 1970, a cultura acadêmica dos dois países enfatizava que as universidades deveriam ter um grau elevado de autonomia institucional e desempenhar um papel democratizante. Esse papel não se limitava a promover oportunidades para uma mobilidade social, política e econômica, mas buscava também fornecer um exemplo de instituição pública cujas estruturas e práticas obedeciam a princípios democráticos de gestão. Durante aquele período, o sistema de ensino superior dos dois países era predominantemente composto por instituiçōes públicas (com uma presença irrelevante de instituiçōes privadas) com mensalidades baixas ou inexistentes. Aqueles também foram anos de expansão do número de matrículas, a qual foi estimulada pela consolidação do Estado-Providência e pela popularidade da teoria do capital humano, que recomendava investimentos maiores em educação e ciência. Essa expansão também foi possibilitada pelo crescimento sustentado, pelo qual essas duas economias estavam passando (agricultura, mineração etc.), e pela expressiva redistribuição dos lucros por meio de investimentos públicos.

Durante o período pós-guerra, na cultura acadêmica dominante dos dois países, o ensino superior era considerado um bem público feito para melhorar o bem público. Essa percepção permeava o ethos que norteava as atividades de pesquisa, ensino e extensão e se baseava em modelos tradicionais de universidade que, em parte, remontavam à Idade Média (como a idéia de refúgios acadêmicos não contaminados), mas também às contribuições mais recentes (modernistas), como as Luzes, o positivismo, o liberalismo e o marxismo. A relação com as empresas, naquela época restrita a um pequeno grupo de pesquisadores, era, para muitos acadêmicos dos dois países, quer um conceito alheio quer uma questão problemática.

No fim dos anos de 1970, o contrato social do Estado-Providência começou a entrar em crise, e as políticas neoliberais implementadas por Reagan nos EUA e Thatcher na Inglaterra marcaram o início de uma nova era global. A nova ideologia dominante era explicitamente favorável ao mercado, e concebia o Estado como um obstáculo para uma economia eficiente. Durante aqueles anos, a cultura acadêmica tradicional começou a ser substituída por um novo paradigma que primeiro aceitou e mais tarde endossou o papel da empresa privada nos esforços 
universitários. Isso era muito mais patente nas ciências que nas humanidades, mas a mudança ideológica ocorreu nas duas tribos acadêmicas.

Situamos o ponto de inflexão dessa mudança no começo dos anos de 1980, quando um impulso para a institucionalização da cooperação universidade-empresa ocorreu nos dois países. Em 1983, uma Oficina de Transferência de Tecnologia foi criada no Consejo Nacional de Investigaciones Cientificas y Tecnológicas (CONICET) na Argentina, e um Corporate-Higher Education Forum (Fórum Empresas-Ensino Superior) foi organizado no Canadá. Embora a relação universidade-empresa tenha existido, até um certo ponto, durante todo o século passado, essa tendência passou a ser muito mais profunda e global. Nas duas últimas décadas, a transferência de tecnologia das universidades para a empresa tem proliferado no mundo inteiro, levando a maior comercialização do trabalho acadêmico. Tanto em nações desenvolvidas como em países em desenvolvimento, mais pesquisadores estão transferindo seus resultados para empresas industriais e novos escritórios de transferências de tecnologia estão sendo construídos em campi universitários. Muitos pesquisadores universitários, que costumavam situar-se entre capital e trabalho, estão se posicionando firmemente no mercado (Axelrod, 1982, 1986, 2002; Slaughter \& Leslie, 1997). Além do mais, em alguns países, líderes políticos e empresariais concebem as universidades principalmente como extensóes do Estado e como instalações de P\&D para o avanço industrial.

$\mathrm{Na}$ Argentina e no Canadá, a cultura acadêmica não saiu ilesa desses processos e do novo quadro ideológico que promoveram. Depois do processo inicial, que datamos simbolicamente de 1983, alguns grupos organizaram um curto período de resistência, mas, de modo geral, a maioria dos membros da comunidade acadêmica não se envolveu nele. Entre a minoria dos que se preocuparam com as implicações desse novo rumo, apenas um pequeno grupo de acadêmicos dos dois países (particularmente no Canadá) alertou contra os riscos potenciais de se adotar uma relação mais estreita com os negócios, palavras que tiveram pouco impacto.

De modo geral, entre aqueles que se preocupavam não havia uma crença firme de que uma relação universidade-empresa mais estreita fosse realmente uma ameaça para o trabalho acadêmico. Muitos pensavam que essa situação seria temporária e que desapareceria assim que os cor- 
tes de orçamento fossem eliminados ou reduzidos. Outros pensavam que ninguém imporia mudanças drásticas aos acadêmicos sem seu consentimento, que as relaçôes universidade-mercado sempre ficariam marginais e não no cerne das atividades acadêmicas e que o ethos acadêmico não toleraria a institucionalização de um "casamento" estável com os negócios. No fim dos anos de 1990, contudo, as mudanças na cultura acadêmica já eram claras e perceptíveis. Ao passo que nas décadas anteriores a grande maioria acreditava que relações mais fortes com a empresa fossem improváveis, temporárias ou indesejadas, mais pesquisadores começavam a mudar de idéia e aceitavam o novo papel da universidade como inevitável, permanente e até desejável.

\section{Recebido e aprovado em setembro de 2004.}

\section{Notas}

1. A autonomia é a qualidade ou o estado de quem é independente, livre, e autogovernado. A heteronomia designa a sujeição a controles e imposiçōes externos, isto é, a subordinação à lei ou dominação de outro. A universidade heterônoma resulta da combinação de duas dimensões aparentemente contraditórias: "intervencionismo" e "laissez-faire". A agenda universitária é cada vez mais condicionada pelas exigências do mercado e os imperativos do Estado no modelo heterônomo, o qual envolve tanto uma universidade "comercial" (ou de mercado, empresarial, de serviços ou negócios) como "controlada" (ou "responsiva" ou "responsável") (ver Schugurensky, 1994 e 1999).

2. As características da reforma de 1918 podem ser resumidas assim: a) Institucionalização da participação dos estudantes nos conselhos universitários, num sistema tripartido que incluía professores e alunos (co-governança). b) Vinculação entre políticas estudantis e políticas nacionais para mobilizar a universidade rumo à solução de problemas econômicos, sociais e políticos. c) Preocupação com a extensão universitária, particularmente com cursos para trabalhadores que possam levar a desenvolver laços fraternos com o proletariado. d) Educação gratuita, concebida como um instrumento para alcançar a democratização do acesso, aumentar o número de matrículas para incluir todos os candidatos academicamente qualificados e substituir a universidade elitista, oligárquica e arcaica do século XIX por uma universidade das massas. e) Defesa da autonomia institucional com relação ao Estado. f) Institucionalização de mecanismos para proteger a liberdade acadêmica, inclusive a implementação do "ensino livre" para garantir o pluralismo acadêmico e quebrar o monopólio de ensino que professores mais antigos (catedráticos) desfrutavam. g) Promoção de novas idéias, métodos de ensino inovadores, mudanças no sistema de exames, presença às aulas opcional, pesquisa original e a rejeição dos dogmatismos; todas medidas que levam à substituição da teologia por disciplinas positivistas. h) Seleção por meio de exames abertos e competitivos para se opor ao nepotismo e ao apadrinhamento, e promoção de professores na base do mérito e das realizações, de preferência ao tempo de serviço. i) Expansão e diversificação da formação profissional por meio da criação de novas escolas profissionais. j) Compreensão da vida universitária como uma experiência verdadeiramente comu- 
nitária e estimulação do desenvolvimento de uma população de professores titulares e de estudantes em tempo integral.

3. Um antecedente dessa regulação pode ser encontrado em 1964, quando o primeiro Fundo Especial para Atividades Científicas e Tecnológicas foi proposto para excluir de vez os investimentos estrangeiros das atividades de pesquisa universitária.

4. Para uma lista completa ver: www.perseo.agencia.secyt.gov.ar/ftr/list_uvt.htm.

5. Fondo Tecnológico Argentino; ver: www.agencia.secyt.gov.ar/ftr/fontar.htm.

6. Fondo para la Investigación Cientifica y Tecnológica: ver: www.agencia.secyt.gov.ar/fct/ foncyt.htm.

7. Na realidade, os indícios disponíveis na Argentina sugerem que esse interesse foi historicamente baixo, e focalizava quase exclusivamente a pesquisa aplicada com taxas de retorno em curto prazo (ver Pichel, 1991; Tenti, 1993).

8. No original: "La enorme restricción presupuestaria ha obligado a que las universidades busquen desesperadamente recursos. Y en esa búsqueda están perdiendo mucho de lo que es su esencia. No hay que ver las universidades como empresas sino como ámbitos culturales. Esa ciudad intelectual libre, como siempre fue concebida la Universidad, está siendo brutalmente despedazada por las fuerzas del mercado, que hace que la Universidad se convierta en una proveedora de servicios educativos. Yo creo que la Universidad es otra cosa”. Entrevista com Jaim Etcheverry, publicada no Clarin, 7 abr. 2003.

9. Ver, por exemplo, Zaslove, 1996.

10. É muito interessante ver que um ex-reitor da Universidade de Waterloo publicou recentemente um ensaio em University Affairs em que lamentava que "nos tornamos um pouco 'economocêntricos' demais em nosso foco, em detrimento de alguns outros valores e considerações que estão no cerne de nossa missão” (Downey, 2003, p. 29).

11. Em 1960, apenas $10 \%$ dos formados pelas escolas secundárias ingressaram nalguma universidade. Nos anos de 1990, essa proporção subiu para aproximadamente 40\%. Além do mais, nos anos de 1990 , mais de $20 \%$ dos trabalhadores canadenses tinham obtido créditos universitários, e aproximadamente $23 \%$ tinham um diploma universitário. Isso significa que, no fim do século XX, quase $50 \%$ da mão-de-obra canadense tinha alguma experiência de ensino superior, coisa nunca vista antes no Canadá nem em muitos países.

\title{
Referências bibliográficas
}

\begin{abstract}
ALTBACH, P. Knowledge and education as international commodities: the collapse of the common good. International Higher Education, n. 28, summer 2002. Disponivel em: <www.bc.edu/bc_org/avp/soe/cihe/ newsletter/News28/Newslet28.html> Acesso em: out. 2004
\end{abstract}

\section{AXELROD, P. Scholars and dollars. Toronto: University of Toronto, 1982.}

AXELROD, P. Service or captivity?: business-university relations in the twentieth century. In: NeILSON, W.; GafFIELD, C. (Ed.). Universities in 
Parceria universidade-empresa e mudanças na cultura acadêmica...

crisis: a medieval institution in the twenty-first century. Montreal: Institute of Research on Public Policy, 1986.

AXELROD, P. Values in conflict: the university, the marketplace and the trials of the liberal education. Montreal: McGill Queen's University, 2002.

CALVERT, J.; KUEHN, L. Corporate power, free trade and Canadian education. Toronto: Our Schools Our Selves, 1993.

CORREA C. Contratos de investigación: vinculación universidad-empresa. Revista de Derecho Industrial, Buenos Aires, v. 14, abr. 1992.

CURRIE, J.; NEWSON, J. (Ed.). Universities and globalization: critical perspectives. Thousand Oaks, CA: Sage, 1998.

DURKHEIM, E. The division of labor in society. Trad. G. B. Simpson. Rev. ed. New York: Free, 1984.

ETCHEVERRY, G.J. La universidad está siendo despedazada por el mercado: balance de gestión. Clarin, Buenos Aires, abr. 2003.

FISHER, D.; RUBENSON, K. The changing political economy: the private and public lives of Canadian universities. In: CURRIE, J.; NEWSON, J. (Ed.). Universities and globalization: critical perspectives. Thousand Oaks, CA: Sage, 1998.

GRUPO DE TRABAJADORES DE LA CIENCIA. Actividad científica y realidad nacional. Ciencia Nueva, Buenos Aires, n. 14, 1972.

JACEK, H. The universities are not ready. Ontario Confederation of University Faculty Associations Forum, Toronto, p. 4-6, spring 2003. Disponivel em: <www.ocufa.on.ca/forum/spring03.pdf> Acesso em: out. 2004.

LEWIS, L. Marginal worth: teaching and the academic labor market. New Brunswick, NJ: Transaction, 1996.

LINDENSTEIN, P.; WALSHOK, M. Technology transfer and university extension. In: RoHFeld, R.W. (Ed.). Expanding access to knowledgecontinuing higher education: NUCEA 1915-1990. Washington, DC: National University Continuing Education Association, 1990. p. 195197. 
NAIDORF, J. Universidad, empresa y Estado: un vínculo complejo. Espacios de Critica y Producción, Buenos Aires, n. 29, nov. 2002.

NEWSON, J. The corporate-linked university: from social project to market force. Canadian Journal of Communications, Ontario, v. 23, n. 1, 1998.

NEWSON, J.; BUCHBINDER, H. The university means business: corporations and academic work. Toronto: Garamond, 1988.

NEWSON, J.; BUCHBINDER, H. Corporate-university linkages in Canada: transforming a public institution. Higher Education, n. 20, 1990.

NIVOLI, M. Comercialización de resultados de investigación en Argentina: contratos de investigación, y vinculacion universidad-empresa. Revista de Derecho Industrial, Buenos Aires, v. 14, 1992.

PHILLIPSON, E.A. Conflict of interest at the industrial-academic interface. Canadian Journal of Clinical Pharmacology, v. 8, n. 1, 2001.

PICHEL, R. Desarrollo sin ciencia: otra fantasia argentina. Buenos Aires: Fundación Favaloro, 1991.

POLSTER, C. Compromising positions: the role of the federal government in re-organizing the social relations of academic research in Canada. 1994. Tese (Doutorado), York University, Toronto.

SCHUGURENSKY, D. Global economic restructuring and university change: the case of Universidad of Buenos Aires. 1994. Tese (Doutorado), University of Alberta, Edmonton, Canada. (não publicada)

SCHUGURENSKY, D. Higher education restructuring in the era of globalization: toward a heteronomous model?. In: ARNOVE, R.; TORRES, C.A. (Ed.). Comparative education: the dialectic of the global and the local. Lanham: Rowman \& Littlefield, 1999.

SLAUGHTER, S.; LESLIE, L. Academic capitalism: politics, policies and the entrepreneurial university. Baltimore: Johns Hopkins University, 1997.

SNOW, C.P. Two cultures and the scientific revolution. London: Cambridge University, 1959. 
Parceria universidade-empresa e mudanças na cultura acadêmica...

TENTI, E. (Ed.). Universidad y empresa. Buenos Aires: Miño y Dávila, 1993.

TORNATZKY, L.; WAUGAMAN, P.G.; GRAY, D.O. Innovation U: new university roles in a knowledge economy. Research Triangle Park, NC: Southern Growth Policies Board, 2002.

TURK, J. What commercialization means for education? In: TURK, J. (Ed.). The corporate campus: commercialization and the dangers to Canada's colleges and universities. Halifax, NS: James Lorimer, 2000.

WALFORD, G. The changing relationship between government and higher education in Britain. In: Neave, G.; VAn Vught, F. (Ed.). Prometheus bound. Oxford: Pergamon, 1991.

WISEMAN, N. Conservative stewardship of postsecondary education. Ontario Confederation of University Faculty Associations Forum, Toronto, p. 14-16, spring 2003. Disponivel em: <www.ocufa.on.ca/forum/ spring03.pdf> Acesso em: out. 2004

ZASLOVE, J. Theory, freedom and the university; paper presented at Academic Freedom: the History and Future of a Defining Idea Conference, sept. 1996, University of Saskatchewan, Saskatoon. 